\title{
LIABILITY INSURANCE OF PERSONS THAT MAKE UP THE CORPORATE BODIES OF A LEGAL ENTITY
}

\author{
Irina N. Romanova \\ Ryazan Branch of S.Y. Witte Moscow State University, Ryazan, Russian Federation
}

\begin{abstract}
Introduction: in carrying out the business activities of a risky nature the objectively interested in preventing the negative effects of its implementation, and in the case of such consequences - in minimization, business entities use insurance as the most effective means of protection of property interests. Methods: it is of great interest to reveal the specifics of the practical implementation of Russian business relations developing in the professional sphere by identifying the problem areas and critical analysis of possible solutions. Results: the paper presented in detail the element-by-element structure of the relations in the sphere of liability insurance of the legal entity's corporate bodies; investigated the conditions of such liability insurance. The author explored the practical approaches to the question of proof of the fact of the insured event; justified the circumstances precluding the possibility of providing the insurance cover. Conclusions: as a result of the research the author determines that the liability insurance of persons that make up the corporate bodies of a legal entity is complex, since it includes: the non-contractual liability insurance of a person performing the functions of the executive body of the business entity before the business entity; the business entity for the actions of the head before the third parties; the insurance of financial risks resulting from the expenses incurred during the non-legal and legal proceedings in relation to the asserted claim against the head or another person performing the management functions.

Key words: liability insurance, legal entity, business entity, insurable interest, insured event, insurance coverage, insurance contract, insurer and insured person.
\end{abstract}

УДК $347.45 / .47$

ББК 67.404.213

\section{СТРАХОВАНИЕ ОТВЕТСТВЕННОСТИ ЛИЦ, ВХОДЯЩИХ В СОСТАВ ОРГАНОВ УПРАВЛЕНИЯ ЮРИДИЧЕСКОГО ЛИЦА}

\author{
Ирина Николаевна Романова \\ Рязанский филиал Московского университета им. С.Ю. Витте, г. Рязань, Российская Федерация
}

Введение: в процессе осуществления носящей рисковый характер предпринимательской деятельности хозяйствующие субъекты, объективно заинтересованные в предупреждении негативных последствий ее осуществления, а в случае наступления таких последствий - в их минимизации, применяют страхование как наиболее эффективное средство защиты имущественных интересов. Методы: представляется интересным выявление специфики практической реализации отношений, складывающихся в сфере профессиональной деятельности российских предпринимателей, посредством выявления проблемных аспектов и критического анализа возможных путей их решения. Результаты: в работе подробно рассмотрен поэлементный состав отношений, складывающихся в сфере страхования ответственности органов управления 닥ического лица; исследованы условия страхования такой ответственности. В статье изучены практи군 ческие подходы к вопросу доказанности факта наступления страхового случая; обоснованы обстоятельства, исключающие возможность предоставления страховой защиты. Выводы: в итоге проведенного исследования автором определено, что страхование ответственности лиц, входящих в состав органов юриди-

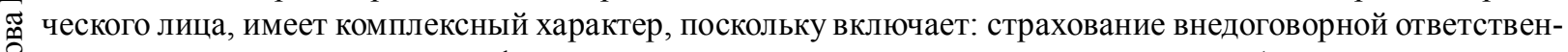
ности лица, осуществляющего функции исполнительного органа хозяйственного общества перед хозяйственным обществом; хозяйственного общества за действия руководителя перед третьими лицами; стра(2) $\mathrm{x}$ 
разбирательства, в связи с требованием, заявленным против руководителя или иного лица, осуществляющего функции управления.

Ключевые слова: страхование ответственности, юридическое лицо, хозяйственное общество, страховой интерес, страховой случай, страховая защита, договор страхования, страховщик и застрахованное лицо.

\section{Введение}

Рисковый характер предпринимательской деятельности порождает объективную потребность в предупреждении и (или) минимизации негативных последствий ее осуществления. При этом наиболее эффективным средством защиты имущественных интересов хозяйствующих субъектов обоснованно признается страхование, роль которого неуклонно возрастает в условиях развития процессов и явлений, приобретающих глобальный характер и в силу этого делающих неэффективными или практически неосуществимыми иные средства защиты бизнеса ввиду объективных трудностей в их прогнозировании и реализации мер индивидуального предупреждения и защиты.

Самостоятельный исследовательский интерес вызывает страхование ответственности лиц, входящих в состав органов управления юридического лица, которое в практике современного российского страхования не столь распространено, что во многом обусловлено имеющимися законодательными пробелами в данной сфере и возникающими вследствие этого проблемами.

\section{Проблемы практической реализации страхования ответственности органов управления юридического лица на этапах его развития}

Историко-ретроспективный анализ генезиса страхования ответственности органов управления юридического лица в России позволяет заключить, что данный вид страхования, несмотря на свою сравнительно непродолжительную в хронологическом масштабе практику применения [в России первый полис D\&O (Direct and Officers Liability) был выдан в 1996 году. Договор страхования был заключен между «Вымпелкомом» и российским подразделением AIG], постепенно вошел в практику корпоративного управления, поскольку «эта модель стра- хования становится для бизнеса не только своего рода правилом хорошего тона, но в некоторых случаях и нормативным требованием» [2, с. 171]. Об этом, в частности, свидетельствует п. 139 Кодекса корпоративного управления (Письмо Банка России от 10 апреля 2014 г. № 06-52/2463), который рекомендует обществу за счет собственных средств осуществлять страхование ответственности членов совета директоров, с тем чтобы в случае причинения убытков обществу или третьим лицам действиями членов совета директоров эти убытки могли быть возмещены. Предполагается, что это позволит не только компенсировать причиненные обществу убытки, но и привлечь в состав совета директоров компетентных специалистов, которые в противном случае опасались бы возможного предъявления к ним крупных исков [8].

Проблема, однако, заключается в том, что вопросы страхования в этой сфере не всегда коррелируют с действующими нормами российского законодательства об ответственности указанной категории лиц. Предполагается, что они обязаны действовать в интересах юридического лица добросовестно и разумно (п. 3 ст. 53 ГК РФ, ч. 1 ст. 71 Федерального закона от 26 декабря 1995 г. № 208-ФЗ «Об акционерных обществах») [14] и в случае нарушения этой обязанности возместить причиненные юридическому лицу убытки по требованию самой организации и (или) его учредителей (участников).

Стоит согласиться с мнением С.П. Коваленко, которая указывает, что «действовать в интересах общества ... означает исполнять конкретные обязанности, предусмотренные уставом общества, ежегодно отчитываться за результаты своей деятельности, не превышать пределы предоставляемых полномочий, не злоупотреблять правом» [7, с. 105].

Именно поэтому, как справедливо отмечает И.А. Турбина, «...рекомендуется избирать в качестве единоличного исполнительного органа хозяйственного общества лицо, 
имеющее безупречную деловую и личную репутацию и обладающее знаниями, навыками и опытом, профессиональной квалификацией, необходимыми для руководства текущей деятельностью общества, добиваясь устойчивого и успешного развития общества» [12, c. 149].

Однако в отношении требований третьих лиц достаточной правовой определенности нет, что отчасти обусловлено спецификой заявляемых ими требований, которые, как правило, адресованы самой компании как самостоятельному субъекту [4, с. 42].

Следует отметить, что возникшую ситуацию не разрешил бы и вносившийся в Государственную Думу проект Федерального закона № 394587-5 «О внесении изменений в отдельные законодательные акты Российской Федерации в части привлечения к ответственности членов органов управления хозяйственных обществ», где предлагалось закрепить право хозяйственного общества заключить договор страхования ответственности лишь в отношении членов совета директоров (наблюдательного совета) общества, лица, занимающего должность единоличного исполнительного органа общества (директора, генерального директора), и членов коллегиального исполнительного органа общества (правления, дирекции), одновременно ограничив сферу его применения требованиями по обязательствам, возникающим вследствие причинения убытков обществу, его акционерам, владельцам иных эмиссионных ценных бумаг общества и (или) иным лицам в результате их неосторожных действий (бездействия).

Существует и проблема с применением предусмотренных действующим законодательством моделей страхования, учитывая, что гражданское законодательство не затрагивает вопросы страхования ответственности руководителей организации. Законодательная регламентация договора обязательного страхования ответственности арбитражного управляющего (ст. 24.1 Федерального закона от 26 октября 2002 г. № 127-Ф3 «О несостоятельности (банкротстве)» [13] ситуацию принципиально не меняет, учитывая, что в данном случае речь скорее идет о страховании профессиональной ответственности, правовом статусе арбитражного управляющего и процедуре его назначения.

\section{Особенности субъектно-объектного состава отношений в сфере страхования ответственности органов управления юридического лица}

В науке достаточно давно дискутируется вопрос о возможности отнесения страхования ответственности руководителей:

1) к страхованию гражданской ответственности за причинение вреда третьим лицам, что сомнительно, учитывая, что убытки возмещаются компании, с которой менеджеры состоят в правоотношениях, вытекающих либо из договора, либо непосредственно из факта избрания на соответствующую должность, а следовательно, она в качестве третьего лица рассматриваться не может;

2) страхованию ответственности по договору, чему препятствует как правовая природа договора, заключаемого с руководителем, который нередко является трудовым, так и законодательные ограничения на использование данного вида страхования, которое возможно лишь в случаях, прямо указанных в законе, и только в отношении самого страхователя (ст. 932 ГК РФ), что исключает покупку полиса компанией для своих директоров;

3) страхованию финансовых рисков, однако этому мешает уже сама природа страхования ответственности руководителей $[15$, с. 36$]$.

Своеобразие возникающих в данном случае отношений побуждает специалистов говорить о страховании гражданской ответственности членов органов управления хозяйственных обществ как о комбинированном страховании [3, с. 6], комплексном институте, включающем: страхование внедоговорной ответственности лица, осуществляющего функции исполнительного органа хозяйственного общества перед хозяйственным обществом, хозяйственного общества за директора перед третьими лицами, а также страхование финансовых рисков, обусловленных расходами, возникшими в ходе внесудебного и судебного разбирательства в связи с требованием, заявленным против директора или иного лица, осуществляющего функции управления [1, с. 9]. 
Объектом страхования в этом случае становятся имущественные интересы, связанные с возможностью возникновения убытков и (или) расходов на защиту, возникших вследствие предъявления к застрахованному лицу руководителю или иным лицам, уполномоченным принимать решения от имени юридического лица, либо к самой компании претензий о возмещении вреда и (или) убытков, причиненных третьим лицам, компании или сотрудникам компании вследствие ошибочных действий, включая расходы, обусловленные возмещением, выплаченным своим директорам по искам, расходы самих директоров, если по закону компания не способна их возместить, расходы компаний по предъявленным против них искам в связи с ошибочными действиями руководителей, связанными с оборотом ценных бумаг и наймом персонала, а также имущественные интересы, связанные с возможностью возникновения убытков и (или) расходов на защиту, возникших вследствие предъявления к застрахованному лицу и (или) компании претензий о возмещении вреда и (или) убытков, причиненных третьим лицам, компании или сотрудникам компании вследствие ошибочных действий директора и (или) компании. При этом сам договор изначально считается заключенным в пользу третьих лиц, которым может быть причинен вред, даже если он заключен в пользу страхователя или иного застрахованного лица, ответственного за причинение вреда, либо в договоре не сказано, в чью пользу он заключен.

В качестве страхователей могут выступать как юридические лица любых организационно-правовых форм, имеющие исполнительный (индивидуальный или коллективный) орган управления либо выполняющие функции управляющей организации, так и физические лица, на которых может быть возложена личная ответственность в связи со своими должностными или иными обязанностями по управлению или надзору, либо являющиеся индивидуальными предпринимателями, осуществляющими деятельность в качестве управляющего юридического лица в связи с передачей им полномочий исполнительного органа.

Заслуживает внимания подход страховщиков к определению круга застрахованных лиц. С одной стороны, он значительно шире по сравнению с традиционным перечнем лиц, относимых к категории руководителей организации, поскольку включает помимо лиц, выступающих в качестве единоличного исполнительного органа (директора, генерального директора и т. д.), в том числе временного единоличного исполнительного органа (управляющая организация или управляющий хозяйственного общества, руководитель унитарного предприятия, председатель кооператива и т. п.), или членов коллегиального органа юридического лица (члены совета директоров (наблюдательного совета), или коллегиального исполнительного органа (правления, дирекции) хозяйственного общества, члены правления кооператива и т. п.), главного юридического советника компании, риск-менеджера (руководитель подразделения управления рисками), любого члена комитета, комиссии и т. п. по внутреннему аудиту, иных руководящих (должностных) лиц, то есть физических лиц в должности руководителя (начальника) любого из подразделений компании с должностными обязанностями по управлению или надзору, и работников организации, в связи с ошибочными действиями которых может быть предъявлено требование, связанное с трудовыми отношениями, или которые могут быть названы соответчиками по любым требованиям ко всем вышеуказанным субъектам.

Как правило, по договору может быть застрахован риск ответственности одного или нескольких лиц. При этом страхованию подлежат:

1) риск ответственности руководителя за причинение вреда третьим лицам вследствие непреднамеренного ошибочного действия при осуществлении своих должностных обязанностей в этом качестве. Однако по данному риску не возмещается убыток, возмещенный или подлежащий возмещению самой компанией;

2) риск ответственности организации за причинение вреда третьим лицам вследствие непреднамеренного ошибочного действия руководителя при осуществлении им своих должностных обязанностей в этом качестве;

3) риск возникновения у организации расходов, связанных с возмещением убытков по предъявленным к ее руководителю требованиям;

4) риск возникновения у руководителя или организации внесудебных и/или судебных 
расходов, а также расходов на связи с общественностью в результате предъявления требований в связи с ошибочным действием руководителя.

Таким образом, страховой интерес в рассматриваемом виде страхования имеет две составляющие, поскольку, с одной стороны, связан с необходимостью нести ответственность за ущерб, причиненный компании или третьим лицам, а с другой - нести расходы, связанные с реализацией права на защиту своих интересов. Указанное обстоятельство дает повод некоторым ученым рассматривать данный вид страхования как комбинированный [3, с. 7].

Следует учитывать и то, что если руководитель и компания вступают в договор такого рода, каждый из них рассматривается как отдельно застрахованный со своим собственным страховым интересом и недобросовестность одного из них не затрагивает остальных.

\section{Факт наступления страхового случая и отказ в страховой защите: \\ основные критериальные показатели}

О возникновении страхового случая можно говорить только при наличии достаточных оснований для привлечения такого лица к ответственности. При этом нельзя не учитывать, что страховая защита предоставляется лишь при причинении вреда вследствие непреднамеренных ошибочных действий и решений руководителя, допущенных в процессе выполнения им своих должностных обязанностей, что вполне согласуется с общим запретом на страхование противоправных интересов, поскольку страхование имущественной ответственности за совершенное административноеправонарушение или преступление повлекло бы фактическое уклонение от негативных последствий, связанных с возложением ответственности за нарушение правовой нормы [2, c. 173]. Дополнительным аргументом является и то, что в соответствии со ст. 963 ГК РФ страховщик освобождается от выплаты страхового возмещения или страховой суммы, если страховой случай наступил вследствие умысла страхователя, выгодоприобретателя или застрахованного лица.

Характеристика самих непреднамеренных ошибочных действий в отсутствие нор- мативного регулирования дается страховщиками по-разному. Так, Правила страхования ответственности директоров, должностных лиц и компании № 143.1, утвержденные приказом ЗАО «МАКС» от 23 мая 2013 г. № 159ОД (А) [11], относят к ним ошибочные или дезориентирующие заявления, упущения, нарушения по небрежности должностных обязанностей, нарушение простых условий о полномочиях, а также иные действия (бездействие), на основании которых и исключительно в связи с исполнением им должностных обязанностей в качестве руководителя к нему предъявляется требование. В Правилах страхования ответственности директоров и должностных лиц юридического лица, утвержденных приказом генерального директора ОАО «Альфа Страхование» от 28 января 2008 г. [10], под неверным (ошибочным) действием понимается любое реально совершенное или предполагаемое нарушение должностных обязанностей, обязательств; халатность, ошибка, неверное или вводящее в заблуждение заявление, неосторожность, бездействие или иное действие руководителя или должностных лиц компании при осуществлении ими своих обязанностей в качестве таковых.

Очевидно, что наступившие негативные последствия сами по себе не свидетельствуют о недобросовестности и (или) неразумности действий (бездействия) руководителя, поскольку возможность их возникновения обусловлена самим рисковым характером предпринимательской деятельности [5, с. 121]. Соответственно при установлении факта наступления страхового случая должны быть приняты во внимание обычные условия делового оборота и иные обстоятельства, имеющие значение для дела. И если негативные последствия вызваны неблагоприятной рыночной конъюнктурой, недобросовестностью выбранного контрагента, работника или представителя юридического лица, неправомерными действиями третьих лиц, авариями, стихийными бедствиями и иными подобными событиями, говорить о юридической ответственности руководителя, а следовательно, о наступлении страхового случая нет оснований.

В то же время характеристика действий и решений руководителя как непреднамеренных исключает возможность предоставления 
страховой защиты при установлении его умысла, являющегося неотъемлемой характеристикой недобросовестности поведения, о которой можно говорить, если руководитель:

1) действовал при наличии конфликта между его личными интересами (интересами аффилированных лиц директора) и интересами юридического лица, в том числе при наличии фактической заинтересованности в совершении юридическим лицом сделки, за исключением случаев, когда информация о конфликте интересов была заблаговременно раскрыта и действия директора были одобрены в установленном законодательством порядке;

2) скрывал информацию о совершенной им сделке от участников юридического лица (в частности, если сведения о такой сделке в нарушение закона, устава или внутренних документов юридического лица не были включены в отчетность юридического лица) либо предоставлял участникам юридического лица недостоверную информацию в отношении соответствующей сделки;

3) совершил сделку без требующегося в силу законодательства или устава одобрения соответствующих органов юридического лица;

4) после прекращения своих полномочий удерживает и уклоняется от передачи юридическому лицу документов, касающихся обстоятельств, повлекших неблагоприятные последствия для юридического лица;

5) знал или должен был знать о том, что его действия (бездействие) на момент их совершения не отвечали интересам юридического лица, например, совершил сделку (голосовал за ее одобрение) на заведомо невыгодных для юридического лица условиях или с заведомо неспособным исполнить обязательство лицом («фирмой-однодневкой» и т. п.). При этом предполагается, что интересы коммерческой организации связаны с извлечением прибыли, а содержание ее деятельности определяется учредительными документами и решениями органов юридического лица. Кроме того, нельзя признать директора действовавшим в интересах юридического лица, если он действовал в интересах одного или нескольких его участников, но в ущерб юридическому лицу.

Неразумность действий, напротив, при недоказанности умысла руководителя не пре- пятствует получению страхового возмещения. Речь идет о случаях, когда он: принял решение без учета известной ему информации, имеющей значение в данной ситуации; до принятия решения не предпринял действий, направленных на получение необходимой и достаточной для его принятия информации, которые обычны для деловой практики при сходных обстоятельствах, в частности, если доказано, что при имеющихся обстоятельствах разумный директор отложил бы принятие решения до получения дополнительной информации; либо совершил сделку без соблюдения обычно требующихся или принятых в данном юридическом лице внутренних процедур для совершения аналогичных сделок (например, согласования с юридическим отделом, бухгалтерией и т. п.) [9].

В особую категорию иногда выделяют неверные действия в отношении работников, означающие действительное или утверждаемое: неоправданное или неправильное увольнение, освобождение от должности или прекращение найма на работу, уже осуществленное или в ходе такового, являющееся нарушением закона, любого письменного, выраженного или применимого контракта о найме на работу; вводящее в заблуждение представление или реклама найма на работу; отказ в приеме на работу или в продвижении по службе, необоснованное сдерживание карьерного роста, необоснованные дисциплинарные меры и т. п. [10] Их характеристика показывает, что в подобных случаях форма вины работодателя принципиального значения не имеет.

Следует отметить, что страховщики поразному подходят к вопросу о доказанности факта наступления страхового случая. В одних случаях достаточно необходимости несения расходов на защиту, что весьма актуально, когда речь идет о предполагаемом нарушении. Они могут включать судебные издержки, сборы, а также иные юридические расходы, обоснованно и разумно понесенные в судах при возбуждении исков в связи с ошибочными действиями, покрываемыми рассматриваемым видом страхования, при защите в ходе судебных разбирательств, апелляций и других процедур, а также расходов по апелляциям, наложению ареста и аналогичным действиям. При этом несение необходимых и 
целесообразных расходов по предварительному выяснению обстоятельств причинения вреда, степени виновности страхователя (застрахованного лица, руководителя) и внесудебной защите его интересов в связи с такими случаями признается страховыми случаями при условии, что они согласованы со страховщиком. Получения предварительного согласия также требуют расходы на связи с общественностью, включая выплату вознаграждения консультантам с целью минимизации неблагоприятного влияния на репутацию страхователя (застрахованного), оказанного предъявленным к нему требованием.

\section{Выводы}

Полагаем, страхование ответственности лиц, входящих в состав органов юридического лица, имеет комплексный характер, поскольку включает: страхование внедоговорной ответственности лица, осуществляющего функции исполнительного органа хозяйственного общества перед хозяйственным обществом; хозяйственного общества за действия руководителя перед третьими лицами; страхование финансовых рисков, обусловленных расходами, возникшими в ходе внесудебного и судебного разбирательства в связи с требованием, заявленным против руководителя или иного лица, осуществляющего функции управления.

При этом страховой интерес имеет две составляющие, поскольку, с одной стороны, он связан с необходимостью нести ответственность за ущерб, причиненный компании или третьим лицам, а с другой - нести расходы, связанные с реализацией права на защиту своих интересов, несмотря на то что страховая защита предоставляется лишь при причинении вреда вследствие непреднамеренных ошибочных действий и решений руководителя, допущенных в процессе выполнения им своих должностных обязанностей, что вполне согласуется с общим запретом на страхование противоправных интересов.

\section{СПИСОК ЛИТЕРАТУРЫ}

1. Алейникова, В. В. Страхование гражданской ответственности единоличных членов коллеги- альных исполнительных органов хозяйственных обществ : автореф. дис. ... канд. юрид. наук / Алейникова Вера Васильевна. - М., 2016. - 27 с.

2. Габов, А. В. Проблемы правового регулирования страхования ответственности руководителей хозяйственных обществ / А. В. Габов, А. Е. Молотников // Закон. - 2012. - № 9. - С. 162-178.

3. Голева, Е. В. Договор страхования ответственности директоров и менеджеров в праве Англии и России: сравнительный анализ : автореф. дис. ... канд. юрид. наук / Голева Елена Валерьевна. - Екатеринбург, 2013. - 26 с.

4. Голева, Е. В. Договор страхования ответственности директоров и менеджеров хозяйственных обществ в праве Англии и России: сравнительный анализ / Е. В. Голева. - М. : Проспект, 2015. $168 \mathrm{c}$.

5. Иншакова, А. О. Новая политика ответственности единоличного исполнительного органа хозяйственного общества при совершении невыгодной сделки / А. О. Иншакова, И. А. Турбина // Вестник Пермского университета. Серия «Юридические науки». - 2014. - Вып. 4 (26). - С. 119-127.

6. Иншакова, А. О. Специфика согласия органа юридического лица на совершение сделки на примере крупных сделок хозяйственных обществ / А. О. Иншакова, И. А. Турбина // Законы России: опыт, анализ, практика. - 2014. - № 12. - С. 38-41.

7. Коваленко, С. П. Особенности привлечения к ответственности органов управления хозяйственного общества / С. П. Коваленко // Вестник Волгоградского государственного университета. Серия 5 , Юриспруденция. - 2014. - № 2 (23). - С. 104-109.

8. Письмо Банка России от 10 апр. 2014 г. № 0652/2463 // Вестник Банка России. - 2014. - № 40.

9. Постановление Пленума Высшего арбитражного суда РФ «О некоторых вопросах возмещения убытков лицами, входящими в состав органов юридического лица» от 30 июля 2013 г. № 6 // Экономика и жизнь. (Бух. прил.). $-2013 .-30$ авг.

10. Правила страхования ответственности директоров и должностных лиц юридического лица : утв. приказом генер. дир. ОАО «Альфа Страхование» от 28 янв. 2008 г. - Электрон. текстовые дан. Режим доступа: http://www.alfastrah.ru/docs/Pravilastrah-otv-directorov-i-doljnostnyh-lic-uridicheskogolica.pdf. - Загл. с экрана.

11. Правила страхования ответственности директоров, должностных лиц и компании № 143.1 : утв. приказом 3АО «МАКС» от 23 мая 2013 г. № 159ОД(А). - Электрон. текстовые дан. - Режим доступа: http://www.makc.ru/upload/RULES/83_otv_direktorov/ Pravila_143.1_OTVST_DIREKTOROV.p.pdf. - Загл. с экрана.

12. Турбина, И. А. Единоличный исполнительный орган хозяйственного общества в системе кор- 
поративного управления / И. А. Турбина // Вестник Волгоградского государственного университета. 2016. - № 1 (30). - С. 145-149.

13. Федеральный закон «О несостоятельности (банкротстве)» от 26 окт. 2002 г. № 127-Ф3 : (ред. от 3 июля 2016 г., с изм. и доп., вступ. в силу с 1 янв. 2017 г.) // Собрание законодательства РФ. - 2002. № 43. - Ст. 4190.

14. Федеральный закон «Об акционерных обществах» от 26 дек. 1995 г. № 208-Ф3 : (ред. от 3 июля 2016 г., с изм. и доп., вступ. в силу с 1 янв. 2017 г.) // Собрание законодательства РФ. - 1996. - № 1. - Ст. 1.

15. Широков, А. В. Правовые вопросы страхования ответственности директоров и иных должностных лиц / А. В. Широков // Предпринимательское право. -2007. - № 4. - С. 36-38.

\section{REFERENCES}

1. Aleynikova V.V. Strakhovanie grazhdanskoy otvetstvennosti edinolichnykh chlenov kollegialnykh ispolnitelnykh organov khozyaystvennykh obshchestv: avtoref. dis. ... kand. yurid. nauk [Liability Insurance of Individual Members of Collegial Executive Bodies of Economic Societies. Cand. jurid. sci. abs. diss.]. Moscow, 2016. 27 p.

2. Gabov A.V., Molotnikov A.E. Problemy pravovogo regulirovaniya strakhovaniya otvetstvennosti rukovoditeley khozyaystvennykh obshchestv [Problems of Legal Regulation of Liability Insurance of Companies' Executives]. Zakon, 2016, no. 9, pp. 162-178.

3. Goleva E.V. Dogovor strakhovaniya otvetstvennosti direktorov $i$ menedzherov $v$ prave Anglii i Rossii: sravnitelnyy analiz: avtoref. dis. ... kand. yurid. nauk [The Contract of Liability Insurance of Directors and Managers in the Law of England and Russia: Comparative Analysis. Cand. jurid. sci. abs. diss.]. Ekaterinburg, 2016. 26 p.

4. Goleva E.V. Dogovor strakhovaniya otvetstvennosti direktorov $i$ menedzherov khozyaystvennykh obshchestv v prave Anglii i Rossii: sravnitelnyy analiz [The Contract of Insurance Liability of Directors and Managers of Business Entities in the law of England and Russia: Comparative Analysis]. Moscow, Prospekt Publ., 2015. 168 p.

5. Inshakova A.O., Turbina I.A. Novaya politika otvetstvennosti edinolichnogo ispolnitelnogo organa khozyaystvennogo obshchestva pri sovershenii nevygodnoy sdelki [The New Policy of Responsibility of the Sole Executive Body of the Economic Society in the Commission of a Bad Bargain]. Vestnik Permskogo universiteta. Seriya "Yuridicheskie nauki", 2014, no. 4 (26), pp. 119-127.

6. Inshakova A.O., Turbina I.A. Spetsifika soglasiya organa yuridicheskogo litsa na sovershenie sdelki na primere krupnykh sdelok khozyaystvennykh obshchestv [The Specifics of Agreement of a Legal Entity to the Transaction on the Example of Large Transactions of Business Entities]. Zakony Rossii: opyt, analiz, praktika, 2014, no. 2, pp. 38-41.

7. Kovalenko S.P. Osobennosti privlecheniya $\mathrm{k}$ otvetstvennosti organov upravleniya khozyaystvennogo obshchestva [Features of Prosecution of Management Bodies of Entities]. Vestnik Volgogradskogo gosudarstvennogo universiteta. Seriya 5, Yurisprudentsiya [Science Journal of Volgograd State University. Jurisprudence], 2014, no. 2 (23), pp. 104-109.

8. Pismo Banka Rossii ot 10 apr. 2014 g. № 06-52/ 2463 [Letter from the Bank of Russia of April 10, 2014 no. 06-52/2463]. Vestnik Banka Rossii, 2014, no. 40.

9. Postanovlenie Plenuma Vysshego arbitrazhnogo suda $\mathrm{RF} \ll \mathrm{O}$ nekotorykh voprosakh vozmeshcheniya ubytkov litsami, vkhodyashchimi v sostav organov yuridicheskogo litsa» of 30 iyulya 2013 g. № 6 [The Decree of the Plenum of the Supreme Arbitration Court of the Russian Federation "On Some Issues of Damage Recovery by Members of Legal Entities" of July 30, 2013 no. 6]. Ekonomika i zhizn (Buhgalterskoe prilozhenie) [Economy and Life (accounting appendix)], 2013, August 30.

10. Pravila strakhovaniya otvetstvennosti direktorov i dolzhnostnykh lits yuridicheskogo litsa: utv. prikazom gener. dir. OAO "Alfa Strakhovanie» ot 28 yanv. $2008 \mathrm{~g}$. [The Rules of Liability Insurance of Directors and Officials of a Legal Entity: Approved by the Order of the General Director of Alpha Insurance JSC of January 28, 2008]. URL: http://www. alfastrah.ru/ docs/Pravila-strah-otv-directorov-i-doljnostnyh-licuridicheskogo-lica.pdf.

11. Pravila strakhovaniya otvetstvennosti direktorov, dolzhnostnykh lits $i$ kompanii № 143.1: utv. prikazom ZAO «MAKS» ot 23 maya $2013 \mathrm{~g}$. № 159-OD $(A)$ [The Rules of Liability Insurance of Directors and Officials and a Company no 143.1: approved by the Order of MAKS CJSC of May 23, 2013 no 159-OD(A)]. URL: http://www.makc.ru/upload/ RULES/83_otv_direktorov/Pravila_143.1_ OTVST_DIREKTOROV.pdf.

12. Turbina I.A. Edinolichnyy ispolnitelnyy organ khozyaystvennogo obshchestva $\mathrm{V}$ sisteme korporativnogo upravleniya [The Sole Executive Body of the Economic Company in Corporate Governance System]. Vestnik Volgogradskogo gosudarstvennogo universiteta. Seriya 5, Yurisprudentsiya [Science Journal of Volgograd State University. Jurisprudence], 2016, no. 1 (30), pp. 145-149.

13. Federalnyy zakon $« \mathrm{O}$ nesostoyatelnosti (bankrotstve)» ot 26 okt. 2002 g. № 127-FZ : (red. ot 3 iyulya 2016 g., s izm. i dop., vstup. v silu s 1 yanv. 2017 g.) [The Federal Law “On Insolvency(Bankruptcy)" ofOctober 26, 2002 no. 127-FL: (amend. of July 3, 2016, 
with amend. and add., entered into force on January 01, 2017)]. Sobranie zakonodatelstva RF, 2002, no. 43, art. 4190 .

14. Federalnyy zakon «Ob aktsionernykh obshchestvakh» ot 26 dek. 1995 g. № 208-FZ : (red. ot 3 iyulya 2016 g., s izm. i dop., vstup. v silu s 1 yanv. 2017 g.) [The Federal Law "On Joint Stock Companies" of December 26, 1995 no. 208-FL: (amend. of July 3, 2016, with amend. and add., entered into force on January 1, 2017)]. Sobranie zakonodatelstva RF [Collected Legislation of the Russian Federation], 1996, no. 1, art. 1.

15. Shirokov A.V. Pravovye voprosy strakhovaniya otvetstvennosti direktorov i inykh dolzhnostnykh lits [Legal Issues of Liability Insurance for Directors and Other Officials]. Predprinimatelskoe pravo, 2007, no. 4, pp. 36-38.

\section{Information about the Author}

Irina N. Romanova, Candidate of Juridical Sciences, Dean of the Law Faculty, Ryazan Branch of S.Y. Witte Moscow State University, Prosp. Pervomayskiy, 62, 390013 Ryazan, Russian Federation, Vip_IrinaRomanova@list.ru,info@ryazan.miemp.ru.

\section{Информация об авторе}

Ирина Николаевна Романова, кандидат юридических наук, декан юридического факультета, Рязанский филиал Московского университета им. С.Ю. Витте, просп. Первомайский, 62, 390013 г. Рязань, Российская Федерация, Vip_IrinaRomanova@list.ru, info@ryazan.miemp.ru. 